\title{
Educação Permanente em Saúde nos Centros de Atenção Psicossocial: revisão integrativa da literatura
}

\author{
Permanent Health Education in Psychosocial Care Centers: \\ integrative literature review \\ Mússio Pirajá Mattos $\mathbf{1 , 2}$, Hudson Manoel Nogueira Campos², Daiene Rosa Gomes², Lorena \\ Ferreira', Raquel Baroni de Carvalho', Carolina Dutra Degli Esposti
}

DOI: $10.1590 / 0103-1104202012724$

RESUMO Este estudo objetivou compreender a apropriação da Educação Permanente em Saúde (EPS) no contexto dos Centros de Atenção Psicossocial (Caps), e suas iniciativas no Brasil, por meio de uma revisão integrativa da literatura. Buscaram-se textos em português, inglês e espanhol, publicados no Brasil entre 2007 e 2019, que abordassem o conceito de EPS, cujos objetivos se referiam a iniciativas desenvolvidas nos Caps, e que versassem sobre as percepções quanto à mudança da prática profissional a partir dessas iniciativas. Foram selecionados 28 estudos. A análise de conteúdo temática identificou quatro categorias empíricas: 1. Concepções de EPS nos Caps; 2. Produção do cuidado e a aproximação com a EPS nos Caps; 3. Fatores intervenientes e características da EPS nos Caps; e 4. Fatores facilitadores e dispositivos de EPS nos Caps. A compreensão de EPS por profissionais e gestores aproxima-se do conceito de Educação Continuada, embora reconheçam que a primeira possibilita a reflexão e a problematização das práticas. As ações de formação desenvolvidas ainda estão distantes das transformações desejadas no âmbito da saúde mental. Considera-se necessário fortalecer a relação entre profissionais, gestores, comunidade e instituições de ensino para que essa política se torne eficaz no modelo de atenção psicossocial.

PALAVRAS-CHAVE Educação permanente. Políticas públicas de saúde. Capacitação de recursos humanos em saúde. Saúde mental. Serviços de saúde mental.

1 Universidade Federal do Espírito Santo (Ufes), Centro de Ciências da Saúde (CCS) - Vitória (ES), Brasil.

mussio.mattos@ufob.edu.br

2 Universidade Federal do Oeste da Bahia (Ufob), Centro das Ciências Biológicas e da Saúde (CCBS) - Barreiras (BA), Brasil.

\begin{abstract}
This study aimed to understand the appropriation of Permanent Health Education (EPS) in the context of the Psychosocial Care Centers (Caps), and their initiatives in Brazil, through an integrative literature review. We searched for texts published in Portuguese, English and Spanish, published in Brazil, between 2007 and 2019, which addressed the concept of EPS, whose objectives referred to initiatives developed at Caps, and which discussed the perceptions regarding the change in professional practice based on these initiatives. 28 studies were selected. Thematic content analysis identified four empirical categories: 1. Conceptions of EPS at Caps; 2. Production of care and approximation with EPS at Caps; 3. Intervening factors and characteristics of EPS at Caps; and 4. Enabling factors and EPS devices in the Caps. The understanding of EPS by professionals and managers comes close to the concept of Continuing Education, although they recognize that EPS allows reflection and problematization of practices. The training actions developed are still far from the desired transformations in the scope of mental health. It is considered necessary to strengthen the relationship between professionals, managers, community and educational institutions so that this policy becomes effective in the model of psychosocial care.
\end{abstract}

KEYWORDS Permanent education. Public health policies. health human resource training. Mental health. Mental health services. 


\section{Introdução}

Apesar de já ter obtido alguns avanços, a formação dos profissionais de saúde no Brasil não tem sido suficiente para a mudança das práticas ${ }^{1}$, inclusive na área da saúde mental. Logo, há uma necessidade crescente de formação e desenvolvimento desses profissionais, a partir de ações de educação permanente, com o intuito de ressignificar seus perfis de atuação, para o fortalecimento da atenção à saúde no Sistema Único de Saúde (SUS). A Educação Permanente em Saúde (EPS) surgiu na década de 1980 e foi disseminada pelo Programa de Desenvolvimento de Recursos Humanos, da Organização Pan-Americana da Saúde (Opas) ${ }^{\mathbf{2}, 3}$. Desde então, começou a ser estruturada pelas controvérsias presentes em sua nomenclatura ${ }^{4}$.

Considerando que o Artigo 200 da Constituição Federal de 1988 estabeleceu que cabem ao SUS o ordenamento e a formação dos recursos humanos na área da saúde 5 , iniciativas foram tomadas entre elas, a criação, pelo Ministério da Saúde (MS), da Secretaria de Gestão de Trabalho e da Educação em Saúde (SGTES), no ano de 2003 com a missão de formular políticas orientadoras da formação, gestão, qualificação e regulação dos trabalhadores da saúde no Brasil6. E isso culminou, em 2004, no lançamento da Política Nacional de Educação Permanente em Saúde (PNEPS) ${ }^{7}$, a qual foi alterada, em 2007, pela portaria Gabinete do Ministro/Ministério da Saúde (GM/MS) no $1.996^{8}$, visando fortalecer o SUS.

Nesse marco normativo ${ }^{8}$, a EPS foi compreendida como uma proposta de aprendizagem no trabalho, a partir das relações orgânicas entre o ensino e as ações nos serviços, e entre a docência e a atenção à saúde, bem como das relações entre formação e gestão setorial, desenvolvimento institucional e controle social em saúde. Neste contexto, é importante notar as diferenças conceituais entre os termos EPS e Educação Continuada (EC), que muitas vezes vem sendo erroneamente utilizados enquanto sinônimos no Brasil. A EC objetiva a atualização do trabalhador, complementando a sua formação ao apoiá-lo em atividades institucionais. Há o predomínio de uma concepção de educação instrumental, organizada de forma vertical, com cursos e treinamentos ${ }^{9,10}$. Por outro lado, a EPS valoriza o trabalho como fonte de saberes, colocando na sua organização a noção de aprendizagem significativa, que vincula esta aprendizagem à problematização dos processos"1"

Assim, a EPS constitui uma iniciativa especialmente importante no campo da saúde mental, uma vez que um dos grandes desafios da Política Nacional de Saúde Mental (PNSM) brasileira é a adequada formação de profissionais para o trabalho intersetorial e interdisciplinar, que produza a superação do paradigma da tutela e do estigma do preconceito ${ }^{12}$. Por este olhar, o movimento da Reforma Psiquiátrica Brasileira (RPB) consiste em um campo frutífero, promissor e vigoroso de transformação da saúde mental e da psiquiatria no mundo ${ }^{\mathbf{1 3}}$. Nesta direção, o tratamento deixa de ser a exclusão e os espaços de violência, e passa a estimular profissionais, usuários e familiares a se tornarem os novos protagonistas do cuidado ${ }^{\mathbf{1 4}}$.

Para isso, a Rede de Atenção Psicossocial (Raps) se esforça para integrar espaços essenciais para o cuidado em saúde mental: a Atenção Primária à Saúde (APS), na qual estão alocadas as Unidades Básicas de Saúde, os Núcleos Ampliados de Saúde da Família, as Equipes de Consultórios de Rua e os Centros de Convivência e Cultura; a Atenção Especializada, que conta com os Centros de Atenção Psicossocial (Caps) em suas modalidades; a Atenção de Urgência e Emergência; a Atenção Residencial de Caráter Transitório; a Atenção Hospitalar; e as Estratégias de Desinstitucionalização, com os Serviços Residenciais Terapêuticos e o Programa de Volta para Casa ${ }^{15}$.

Destaca-se que os Caps constituem núcleos fundamentais para responder às principais necessidades de cuidados dos pacientes que sofrem de transtornos mentais graves e persistentes ${ }^{16}$. Estes dispositivos estão pautados no atendimento territorializado e enfatizam a importância da inclusão da família no tratamento e na reabilitação ${ }^{\mathbf{1 4}, 15}$. Entretanto, na saúde mental, as formações tradicionais de seus profissionais são caracterizadas pelo modelo biomédico ${ }^{17}$, o que distancia, por 
vezes, suas abordagens dos aspectos desafiadores da RPB e da PNSM. Além disto, Guimarães e Rosa $^{18}$ destacam a clara intenção de uma reintrodução da lógica manicomial para os assistidos dos serviços de saúde. Desta forma, torna-se importante repensar e reestruturar estratégias de formação profissional em consonância com os desafios da política de saúde mental19 e centradas nas necessidades da população 16,20-22.

Nessa perspectiva, a forma como a EPS é realizada nos Caps passa a ser o divisor de águas diante das novas demandas ${ }^{23}$, ampliando a relação ensino-aprendizagem que deve existir no processo de trabalho. Ou seja, problematiza o objetivo da saúde mental, implicando mudanças nas práticas e nos saberes, que são apostas fundamentais da RPB e da PNSM, sendo importante compreender a EPS dentro do SUS e na geração de mudanças no cotidiano dos Caps. Neste sentido, o objetivo do presente estudo é compreender a apropriação da EPS no contexto dos Caps e suas iniciativas no Brasil, por meio de uma revisão integrativa da literatura.

\section{Material e métodos}

Trata-se de um estudo de revisão integrativa da literatura sobre a EPS nos Caps. Este tipo de revisão busca sistematizar o conhecimento científico disponível, aproximando o pesquisador da problemática que deseja apreciar, possibilitando conhecer a evolução do tema ao longo do tempo e visualizar oportunidades, lacunas ou questões de pesquisa ${ }^{24}$.

Seis etapas ${ }^{25}$ foram utilizadas para a construção desta revisão: (i) identificação da questão norteadora da pesquisa; (ii) estabelecimento de critérios de inclusão/exclusão de artigos; (iii) definição de informações a serem extraídas dos artigos selecionados; (iv) avaliação dos estudos incluídos na revisão integrativa; (v) análise de dados; e (vi) interpretação dos resultados e apresentação da revisão.

Foi utilizado o guideline Prisma ${ }^{26}$ para sistematizar o processo de pesquisa da presente revisão. O estudo partiu da seguinte questão norteadora:
'Como a EPS tem sido apropriada pelos Caps?'. Além desta, pelas questões específicas: 'Como está caracterizada, conceitualmente, a EPS nos Caps?' e 'Quais os resultados obtidos a partir das iniciativas de EPS nos Caps?'.

Para a seleção dos trabalhos, foram considerados os seguintes critérios de inclusão: artigos originais de trabalhos que abordassem o conceito de EPS e o seu desenvolvimento nos Caps, no Brasil; trabalhos cujos objetivos se referissem a iniciativas de EPS desenvolvidas nos Caps; e trabalhos sobre percepções quanto à mudança da prática profissional a partir dessas iniciativas. $\mathrm{O}$ levantamento compreendeu trabalhos publicados nos idiomas português, inglês e espanhol, no período de 2007 a 2019. Tal recorte foi definido por contemplar o período de vigência da Portaria $\mathrm{n}^{\mathrm{o}}$ 1.996/2007 da PNEPS 4,8 .

Foram excluídos os trabalhos duplicados, portarias, editoriais, artigos de opinião, relatos de experiência, monografias, teses e dissertações, bem como os documentos e resumos de seminários, congressos, cursos e aqueles não encontrados na íntegra. A busca da literatura e a seleção das publicações foram realizadas por dois revisores, de forma independente, nas seguintes bases de dados: Biblioteca Virtual em Saúde (BVS), Lilacs (Literatura Latino-Americana e do Caribe em Ciências da Saúde), Medline (Medical Literature Analysis and Retrieval Sistem on-line), SciELO (Scientific Electronic Library Online); BDENF (Base de Dados de Enfermagem); Google Acadêmico; e Scopus (SciVerseScopus).

Os descritores utilizados para busca foram selecionados a partir do vocabulário estruturado Descritores em Ciências da Saúde (DeCS), em português, inglês e espanhol: 'educação permanente', 'permanent education', 'educación permanente', 'educação continuada', 'continuing education', 'educación continua', 'educação permanente em saúde', 'permanent health education', 'educación permanente em salud', 'educação em saúde', 'health education', 'educación em salud', 'saúde mental', 'mental health', 'salud mental', 'serviços de saúde mental', 'mental health services' e 'servicios de salud mental'. Tais descritores foram 
combinados com o auxílio dos operadores booleanos (AND e OR).

Ainda que esta revisão tenha o objetivo de evidenciar a apropriação sobre a temática da EPS desenvolvida nos Caps, no Brasil, a escolha pelo descritor 'educação continuada' se deu por conta da confusão conceitual referente ao termo EPS e, consequentemente, por sua utilização inadequada em textos e artigos científicos. As publicações foram gerenciadas no aplicativo Mendeley (https://www.mendeley.com/), para a remoção das duplicatas. A coleta de dados foi realizada entre os meses de julho e outubro de 2019, utilizando uma planilha do Microsoft Excel $^{\circledR}$, contendo os seguintes termos: base de dados; número total de artigos encontrados; nome do periódico; título do artigo; autores; ano de publicação; região de publicação; e resumo.
A sistematização da seleção das publicações está apresentada em um fluxograma ${ }^{\mathbf{2 6}}$ (figura 1), com a descrição das etapas de busca e o quantitativo de publicações em cada uma das bases. Inicialmente, realizou-se a leitura dos títulos e dos resumos de todas as 2.516 publicações, selecionadas pelos dois revisores de forma independente. Nessa etapa, foram excluídos 2.334 textos, seguindo os critérios de inclusão e exclusão. Estudos com métodos mistos (quantitativo e qualitativo) também foram incluídos.

Em seguida, foi realizada a leitura, na íntegra, de 182 publicações, atentando novamente para os critérios de inclusão e exclusão, o que também auxiliou na categorização das informações extraídas das publicações. Dessa forma, foi atingido um número final de 28 publicações selecionadas para a revisão.

Figura 1. Fluxograma do processo de seleção das publicações para a revisão integrativa

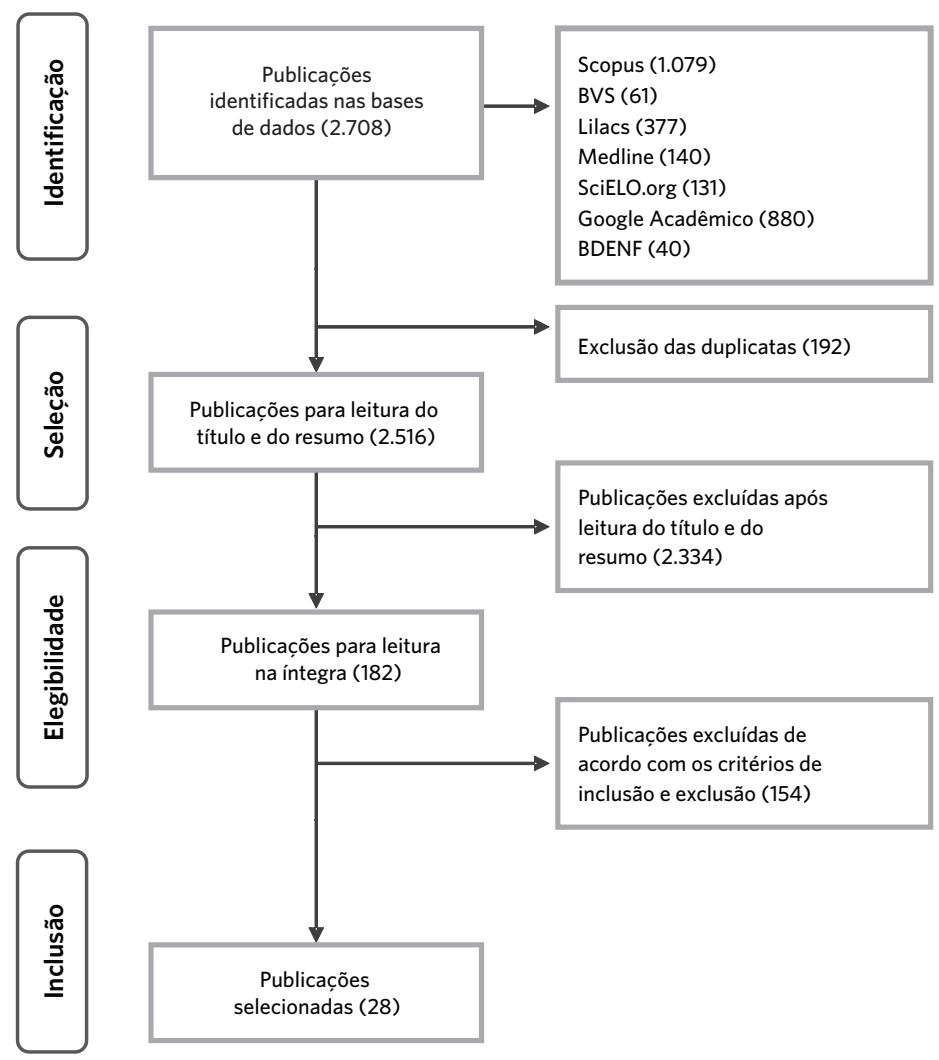


Para o exame dos estudos incluídos, utilizou-se a análise de conteúdo temática ${ }^{27}$. $\mathrm{Na}$ etapa de pré-análise, foi realizada a exploração do material, além do tratamento dos resultados obtidos e sua interpretação. Nessa etapa também foram realizadas a organização das informações e a sistematização das ideias iniciais mediante à leitura flutuante dos dados, destacando elementos principais com a finalidade de identificar possíveis categorias de análise. Na segunda etapa, realizou-se a exploração do material, que consistiu na codificação, classificação e agregação dos dados, e na elaboração das categorias empíricas responsáveis pela especificação do tema: Concepção sobre EPS nos Caps; Produção do cuidado e a aproximação com a EPS nos Caps; Fatores intervenientes e características da EPS nos Caps; e Fatores facilitadores e dispositivos de EPS nos Caps.

Para a avaliação dos estudos qualitativos, foi utilizado o instrumento proposto pelo Critical Appraisal Skills Programme (Casp) ${ }^{28}$, empregado na análise crítica de relatos de pesquisas qualitativas. Este instrumento apresenta dez questões que conduzem o avaliador a pensar de forma sistemática sobre o rigor, a credibilidade e a relevância do estudo, considerando: (i) objetivo claro e justificado; (ii) desenho metodológico apropriado aos objetivos; (iii) procedimentos metodológicos apresentados e discutidos; (iv) seleção da amostra; (v) coleta de dados descrita, instrumentos e processo de saturação explicitados; (vi) explicitação da relação entre pesquisador e pesquisado; (vii) cuidados éticos; (viii) análise densa e fundamentada; (ix) resultados apresentados e discutidos, apontando o aspecto da credibilidade e o uso da triangulação; $\mathrm{e}$ (x) descrição sobre as contribuições e implicações do conhecimento gerado pela pesquisa, bem como suas limitações.

Os artigos foram pontuados, em cada critério, como: 1 - se o critério foi atendido; 0 - se o critério não foi atendido; 0,5 - se o critério foi parcialmente atendido. A pontuação máxima para um trabalho foi 10. Os estudos foram classificados em duas categorias: na categoria A, foram classificados os estudos com alto rigor metodológico, uma vez que preencheram ao menos nove dos dez itens; na categoria B, foram classificados aqueles com moderado rigor metodológico, quando pelo menos cinco dos dez itens foram atendidos; e, para os estudos que atingiram menos de cinco itens, não se aplicou a classificação ${ }^{28-30}$.

\section{Resultados e Discussão}

\section{Características dos estudos selecionados}

Das publicações analisadas para este estudo, 28 foram incluídas na revisão ${ }^{31-58}$. Verificouse que todos os artigos selecionados estavam em português, utilizaram métodos qualitativos, e um apresentou método misto (1/28). Os dados foram organizados expondo as características dessas produções (quadro 1), segundo autores, título, periódico, estratégia de estudo, abordagem de pesquisa e escore Casp. Todos foram publicados entre $2009 \mathrm{e}$ 2019. Observou-se um crescimento no número de publicações dos últimos anos, com um pico em 2017 (7/28). Na avaliação do rigor metodológico, segundo critérios Casp, 7\% dos estudos ${ }^{49,51}$ foram classificados como B (moderado rigor metodológico). As ausências da explicitação entre pesquisador e pesquisado, e dos procedimentos metodológicos apresentados e discutidos, pontuaram negativamente e contribuíram para esse moderado rigor metodológico (gráfico 1). A partir do material selecionado, foram elaboradas quatro categorias empíricas, incluídas nessa revisão integrativa. 
Quadro 1. Características da produção do conhecimento em estudos sobre Educação Permanente em Saúde nos Centros de Atenção Psicossocial, 2009-2019

\begin{tabular}{|c|c|c|c|c|c|}
\hline Autor & Título & Periódico & Estratégia do Estudo & $\begin{array}{l}\text { Abordagem } \\
\text { da Pesquisa }\end{array}$ & $\begin{array}{l}\text { Escore } \\
\text { Casp }\end{array}$ \\
\hline $\begin{array}{l}\text { Pinheiro; Hypólito; } \\
\text { Kantorski (2019)31 }\end{array}$ & $\begin{array}{l}\text { Educação permanente no } \\
\text { processo de trabalho em saúde } \\
\text { mental }\end{array}$ & $\begin{array}{l}\text { Journal of Nursing and } \\
\text { Health }\end{array}$ & $\begin{array}{l}\text { Estudo descritivo e analítico por meio } \\
\text { do círculo hermenêutico-dialético em } \\
\text { um Caps II, em um município do Rio } \\
\text { Grande do Sul }\end{array}$ & Qualitativa & A \\
\hline $\begin{array}{l}\text { Vasconcelos; Barbosa } \\
(2019)^{\mathbf{3 2}}\end{array}$ & $\begin{array}{l}\text { Conhecimento de gestores e } \\
\text { profissionais da Rede de Aten- } \\
\text { ção Psicossocial sobre matri- } \\
\text { ciamento em saúde mental }\end{array}$ & $\begin{array}{l}\text { Ciência, Cuidado e } \\
\text { Saúde }\end{array}$ & $\begin{array}{l}\text { Estudo descritivo e exploratório na } \\
\text { Raps - Caps II e Caps AD III - em } \\
\text { Arcoverde (PE) }\end{array}$ & Qualitativa & A \\
\hline Nunes et al. (2019)33 & $\begin{array}{l}\text { A tecnologia grupal no cuidado } \\
\text { psicossocial: um diálogo entre } \\
\text { pesquisa-ação e educação } \\
\text { permanente em saúde }\end{array}$ & $\begin{array}{l}\text { Revista Texto e Con- } \\
\text { texto Enfermagem }\end{array}$ & $\begin{array}{l}\text { Pesquisa-ação por meio do Arco de } \\
\text { Maguerez, realizada em } 29 \text { Caps de } \\
23 \text { municípios da Região Centro-Oeste } \\
\text { brasileira }\end{array}$ & Qualitativa & A \\
\hline $\begin{array}{l}\text { Silva; Camargo; Bezer- } \\
\text { ra (2018) }\end{array}$ & $\begin{array}{l}\text { Avaliação dos registros de } \\
\text { procedimentos por profissio- } \\
\text { nais de Centros de Atenção } \\
\text { Psicossocial }\end{array}$ & $\begin{array}{l}\text { Revista Brasileira de } \\
\text { Enfermagem }\end{array}$ & $\begin{array}{l}\text { Estudo descritivo e exploratório com } \\
\text { grupos focais em sete Caps do estado } \\
\text { de Goiás }\end{array}$ & Qualitativa & A \\
\hline $\begin{array}{l}\text { Evangelista et al. } \\
(2018)^{\mathbf{3 6}}\end{array}$ & $\begin{array}{l}\text { Residência Integrada em Saúde } \\
\text { Mental: cuidado a Rede de } \\
\text { Atenção Psicossocial }\end{array}$ & $\begin{array}{l}\text { Revista Brasileira em } \\
\text { Promoção da Saúde }\end{array}$ & $\begin{array}{l}\text { Estudo descritivo e analítico por meio } \\
\text { de análise documental e entrevistas } \\
\text { semiestruturadas, com gerentes e } \\
\text { profissionais Caps de quatro municí- } \\
\text { pios do Ceará }\end{array}$ & Qualitativa & A \\
\hline $\begin{array}{l}\text { Wetzel; Kohlrausch; } \\
\text { Pavani et al. (2018)37 }\end{array}$ & $\begin{array}{l}\text { Análise sobre a formação inter- } \\
\text { profissional em serviço, em um } \\
\text { Centro de Atenção Psicossocial }\end{array}$ & $\begin{array}{l}\text { Interface - Comunica- } \\
\text { ção, Saúde e Educação }\end{array}$ & $\begin{array}{l}\text { Estudo de avaliação da Quarta Gera- } \\
\text { ção e círculo hermenêutico-dialético, } \\
\text { com entrevistas em Caps AD de um } \\
\text { município do Rio Grande do Sul }\end{array}$ & Qualitativa & A \\
\hline $\begin{array}{l}\text { Abrahão; Azevedo; } \\
\text { Gomes (2017)40 }\end{array}$ & $\begin{array}{l}\text { A produção do conhecimento } \\
\text { em saúde mental e o processo } \\
\text { de trabalho no Centro de Aten- } \\
\text { ção Psicossocial }\end{array}$ & $\begin{array}{l}\text { Revista Trabalho, } \\
\text { Educação e Saúde }\end{array}$ & $\begin{array}{l}\text { Estudo descritivo por meio de observa- } \\
\text { ção simples e grupo focal em Caps II e } \\
\text { Caps AD no Rio de Janeiro }\end{array}$ & Qualitativa & A \\
\hline Leite; Rocha (2017)41 & $\begin{array}{l}\text { Educação Permanente em } \\
\text { Saúde: como e em que espaços } \\
\text { se realiza, na perspectiva dos } \\
\text { profissionais de saúde de Porto } \\
\text { Alegre (RS) }\end{array}$ & Estudos de Psicologia & $\begin{array}{l}\text { Estudo realizado com entrevistas } \\
\text { semiestruturadas na Raps, com profis- } \\
\text { sionais Caps em Porto Alegre (RS) }\end{array}$ & Qualitativa & A \\
\hline Pinho et al. (2017) ${ }^{\mathbf{4 2}}$ & $\begin{array}{l}\text { Análise da articulação da rede } \\
\text { para o cuidado ao usuário de } \\
\text { crack }\end{array}$ & $\begin{array}{l}\text { Revista Baiana de } \\
\text { Enfermagem }\end{array}$ & $\begin{array}{l}\text { Estudo de avaliação da Quarta Gera- } \\
\text { ção em um Caps AD no município da } \\
\text { Região Metropolitana de Porto Alegre } \\
\text { (RS) }\end{array}$ & Qualitativa & A \\
\hline
\end{tabular}


Quadro 1. (cont.)

\begin{tabular}{|c|c|c|c|c|c|}
\hline Autor & Título & Periódico & Estratégia do Estudo & $\begin{array}{l}\text { Abordagem } \\
\text { da Pesquisa }\end{array}$ & $\begin{array}{l}\text { Escore } \\
\text { Casp }\end{array}$ \\
\hline Ferreira et al. (2017) $\mathbf{4 3}^{3}$ & $\begin{array}{l}\text { Produção do cuidado em saúde } \\
\text { mental: desafios para além dos } \\
\text { muros institucionais }\end{array}$ & $\begin{array}{l}\text { Interface - Comunica- } \\
\text { ção, Saúde e Educação }\end{array}$ & $\begin{array}{l}\text { Estudo por meio de narrativas e diários } \\
\text { de campo, em um Caps III de João } \\
\text { Pessoa (PB) }\end{array}$ & Qualitativa & A \\
\hline $\begin{array}{l}\text { Onocko-Campos et al. } \\
(2017)^{\mathbf{4 4}}\end{array}$ & $\begin{array}{l}\text { Indicadores para a avaliação } \\
\text { dos Centros de Atenção Psi- } \\
\text { cossocial tipo III: resultados de } \\
\text { um desempenho participativo }\end{array}$ & Saúde em Debate & $\begin{array}{l}\text { Estudo avaliativo por meio de processo } \\
\text { participativo nos Caps III, no estado de } \\
\text { São Paulo }\end{array}$ & Qualitativa & A \\
\hline Rézio et al. (2017)45 & $\begin{array}{l}\text { O PET-Redes como transfor- } \\
\text { mador das práticas profissio- } \\
\text { nais de um Centro de Atenção } \\
\text { Psicossocial }\end{array}$ & $\begin{array}{l}\text { Interface - Comunica- } \\
\text { ção, Saúde e Educação }\end{array}$ & $\begin{array}{l}\text { Estudo descritivo e exploratório por } \\
\text { meio de entrevistas semiestruturadas, } \\
\text { com profissionais de um Caps II em } \\
\text { um município do Mato Grosso }\end{array}$ & Qualitativa & A \\
\hline $\begin{array}{l}\text { Vasconcelos et al. } \\
(2016)^{\mathbf{4 6}}\end{array}$ & $\begin{array}{l}\text { Projeto Terapêutico em Saúde } \\
\text { Mental: práticas e processos } \\
\text { nas dimensões constituintes da } \\
\text { atenção psicossocial }\end{array}$ & $\begin{array}{l}\text { Interface - Comunica- } \\
\text { ção, Saúde e Educação }\end{array}$ & $\begin{array}{l}\text { Estudo baseado na hermenêutica por } \\
\text { meio de entrevistas semiestruturadas, } \\
\text { com profissionais de dois Caps na Re- } \\
\text { gião Metropolitana de Fortaleza (CE) }\end{array}$ & Qualitativa & A \\
\hline Salvador; Pio (2016)47 & $\begin{array}{l}\text { Apoio matricial e Capsi: desa- } \\
\text { fios do cenário na implantação } \\
\text { do matriciamento em saúde } \\
\text { mental }\end{array}$ & Saúde em Debate & $\begin{array}{l}\text { Estudo realizado com grupos focais em } \\
\text { um Capsi. }\end{array}$ & Qualitativa & A \\
\hline $\begin{array}{l}\text { Oliveira; Caldana } \\
(2016)^{\mathbf{4 8}}\end{array}$ & $\begin{array}{l}\text { Psicologia e práticas psicosso- } \\
\text { ciais: narrativas e concepções } \\
\text { de psicólogos de Centros de } \\
\text { Atenção Psicossocial }\end{array}$ & $\begin{array}{l}\text { Estudos Interdiscipli- } \\
\text { nares em Psicologia }\end{array}$ & $\begin{array}{l}\text { Estudo realizado com entrevistas } \\
\text { semiestruturadas nos Caps III, Capsi e } \\
\text { Caps AD de um município no estado } \\
\text { do Pará. }\end{array}$ & Qualitativa & A \\
\hline Rosa et al. (2016)49 & $\begin{array}{l}\text { Inovaç̃̃es na formação em } \\
\text { saúde: o programa de edu- } \\
\text { cação pelo trabalho - saúde } \\
\text { mental }\end{array}$ & $\begin{array}{l}\text { Revista Portuguesa de } \\
\text { Enfermagem de Saúde } \\
\text { Mental }\end{array}$ & $\begin{array}{l}\text { Estudo descritivo com entrevistas } \\
\text { semiestruturadas realizadas nos Caps } \\
\text { AD e Capsi Niterói (RJ) }\end{array}$ & Qualitativa & A \\
\hline Costa et al. (2015) & $\begin{array}{l}\text { Desafio do apoio matricial } \\
\text { como prática educacional: } \\
\text { a saúde mental na Atenção } \\
\text { Básica }\end{array}$ & $\begin{array}{l}\text { Interface - Comunica- } \\
\text { ção, Saúde e Educação }\end{array}$ & $\begin{array}{l}\text { Estudo com entrevistas semiestrutu- } \\
\text { radas no Caps III de um município do } \\
\text { estado de São Paulo }\end{array}$ & Qualitativa & A \\
\hline $\begin{array}{l}\text { Azevedo et al. } \\
(2014)^{\mathbf{5 1}}\end{array}$ & $\begin{array}{l}\text { Avaliação da assistência em } \\
\text { saúde, em um Centro de Aten- } \\
\text { ção Psicossocial, na perspecti- } \\
\text { va dos profissionais }\end{array}$ & $\begin{array}{l}\text { Revista Brasileira de } \\
\text { Pesquisa em Saúde }\end{array}$ & $\begin{array}{l}\text { Estudo avaliativo desenvolvido no Caps } \\
\text { III do município de Caicó (RN) }\end{array}$ & $\begin{array}{l}\text { Qualitativa e } \\
\text { Quantitativa }\end{array}$ & B \\
\hline Silva et al. (2013) $5 \mathbf{2}$ & $\begin{array}{l}\text { Desenvolvimento de recursos } \\
\text { humanos para atuar nos servi- } \\
\text { ços de saúde mental }\end{array}$ & $\begin{array}{l}\text { Revista Texto e Con- } \\
\text { texto Enfermagem }\end{array}$ & $\begin{array}{l}\text { Estudo descritivo com entrevistas se- } \\
\text { miestruturadas de coordenadores, em } \\
\text { todos os Caps no interior de Goiás }\end{array}$ & Qualitativa & A \\
\hline $\begin{array}{l}\text { Minozzo; Costa } \\
(2013)^{\mathbf{5 3}}\end{array}$ & $\begin{array}{l}\text { Apoio matricial em saúde } \\
\text { mental entre Caps e Saúde da } \\
\text { Família: trilhando caminhos } \\
\text { possíveis }\end{array}$ & Psico-USF & $\begin{array}{l}\text { Pesquisa-ação com questionários, dis- } \\
\text { cussões, leituras e reflexões no Caps III }\end{array}$ & Qualitativa & A \\
\hline $\begin{array}{l}\text { Minozzo; Costa } \\
(2013)^{\mathbf{5 4}}\end{array}$ & $\begin{array}{l}\text { Apoio matricial em saúde } \\
\text { mental: fortalecendo a Saúde } \\
\text { da Família na clínica da crise }\end{array}$ & $\begin{array}{l}\text { Revista Latinoameri- } \\
\text { cana de Psicopatolo- } \\
\text { gia Fundamental }\end{array}$ & $\begin{array}{l}\text { Pesquisa-ação com questionários, dis- } \\
\text { cussões, leituras e reflexões no Caps III }\end{array}$ & Qualitativa & A \\
\hline $\begin{array}{l}\text { Azevedo; Gondim; } \\
\text { Silva (2013) } 5 \text { 5 }\end{array}$ & $\begin{array}{l}\text { Apoio matricial em saúde } \\
\text { mental: percepção dos profis- } \\
\text { sionais no território }\end{array}$ & $\begin{array}{l}\text { Revista de Pesquisa: } \\
\text { Cuidado é funda- } \\
\text { mental }\end{array}$ & $\begin{array}{l}\text { Estudo descritivo com entrevistas } \\
\text { semiestruturadas de profissionais do } \\
\text { Caps III do município de Caicó (RN) }\end{array}$ & Qualitativa & A \\
\hline $\begin{array}{l}\text { Ballarin; Blanes; Feri- } \\
\text { gato }(2012)^{\mathbf{5 6}}\end{array}$ & $\begin{array}{l}\text { Apoio matricial: um estudo } \\
\text { sobre a perspectiva de profis- } \\
\text { sionais de saúde mental }\end{array}$ & $\begin{array}{l}\text { Interface - Comunica- } \\
\text { ção, Saúde e Educação }\end{array}$ & $\begin{array}{l}\text { Estudo descritivo com entrevistas } \\
\text { semiestruturadas, com profissionais } \\
\text { Caps }\end{array}$ & Qualitativa & A \\
\hline
\end{tabular}


Quadro 1. (cont.)

\begin{tabular}{|c|c|c|c|c|c|}
\hline Autor & Título & Periódico & Estratégia do Estudo & $\begin{array}{l}\text { Abordagem } \\
\text { da Pesquisa }\end{array}$ & $\begin{array}{l}\text { Escore } \\
\text { Casp }\end{array}$ \\
\hline $\begin{array}{l}\text { Vargas; Duarte } \\
\text { (2011)57 }\end{array}$ & $\begin{array}{l}\text { Enfermeiros dos Centros de } \\
\text { Atenção Psicossocial em Álco- } \\
\text { ol e Drogas (Caps AD): a for- } \\
\text { mação e a busca pelo conheci- } \\
\text { mento específico da área }\end{array}$ & $\begin{array}{l}\text { Revista Texto e Con- } \\
\text { texto Enfermagem }\end{array}$ & $\begin{array}{l}\text { Estudo exploratório com entrevistas } \\
\text { semiestruturadas em } 13 \text { Caps do muni- } \\
\text { cípio de São Paulo (SP) }\end{array}$ & Qualitativa & A \\
\hline $\begin{array}{l}\text { Onocko-Campos et al. } \\
(2009)^{\mathbf{5 8}}\end{array}$ & $\begin{array}{l}\text { Avaliação da rede de Centros } \\
\text { de Atenção Psicossocial: entre } \\
\text { a saúde coletiva e a saúde } \\
\text { mental }\end{array}$ & $\begin{array}{l}\text { Revista de Saúde } \\
\text { Pública }\end{array}$ & $\begin{array}{l}\text { Estudo avaliativo realizado com } 20 \\
\text { grupos focais, em seis Caps III de } \\
\text { Campinas (SP) }\end{array}$ & Qualitativa & $A$ \\
\hline
\end{tabular}

Fonte: Elaboração própria.

Gráfico 1. Sumarização do rigor metodológico global de estudos selecionados para revisão integrativa sobre a EPS nos Caps, no Brasil (2009-2019)

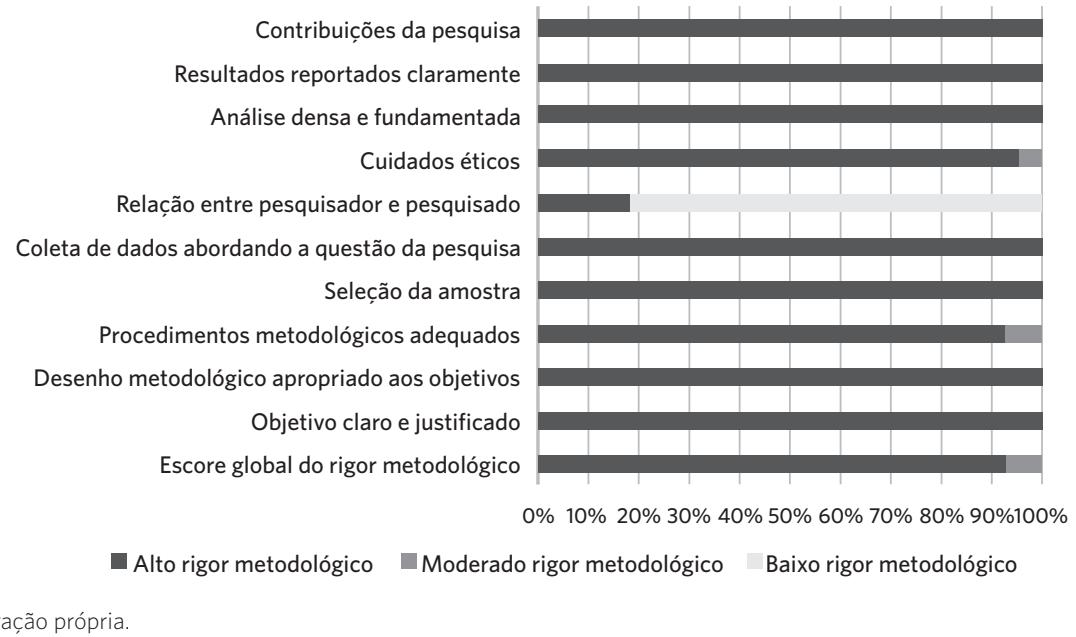

\section{Concepção sobre EPS nos Caps}

Segundo a corrente mais aceita no Brasil, a EPS está fundamentada na concepção de educação como transformação e aprendizagem, centrada na valorização do trabalho como fonte de conhecimento ${ }^{59}$. Neste sentido, a EPS valoriza o trabalho como fonte de saberes, colocando a própria organização do trabalho e da prática cotidiana como base para reflexão e produção de conhecimento, com o desenvolvimento de ações educativas interdisciplinares, contextualizadas com as reais necessidades de saúde e por meio de uma participação coletiva ${ }^{59,60}$.
Os resultados deste estudo apontam compreensões distintas em relação à concepção de EPS. Nesta direção, observa-se que há uma grande necessidade de ações de educação permanente em saúde mental, principalmente, pela especificidade desta área de conhecimento no setor saúde. Também porque muitos profissionais de saúde inseridos nos serviços tiveram sua formação acadêmica anterior ao processo de reforma psiquiátrica. Então, a academia não conseguiu, ao longo do tempo, trabalhar a temática em consonância com a PNSM ${ }^{\mathbf{5 2}}$.

Assim, das 28 publicações, dez $(35,71 \%)$ evidenciaram as concepções de 
EPS31-33,35-37,39,41,43,53. Em alguns estudos, os discursos dos trabalhadores Caps apresentaram uma aproximação com a abordagem problematizadora de Paulo Freire, por meio de uma educação crítica e dialógica, que objetiva, para o educando, uma aprendizagem em termos de cultura, consciência social e política, proporcionando conhecimento de forma organizada e sistematizada, transformando o indivíduo no sujeito social de uma práxis libertadora $\mathbf{3 1}^{\mathbf{3 9}, \mathbf{4 1}}$. Neste sentido, os trabalhadores Caps percebem a EPS como um instrumento de trabalho que possibilita a reflexão e a problematização das práticas, e favorece a sua própria participação na tomada de decisões e no aperfeiçoamento do processo de trabalho. Ou seja, os trabalhadores assumem a tomada de consciência como ponto de partida para o percurso, que vai da aprendizagem à conscientização e ação transformadora 31-33,35-37.

A EPS pautada em concepções freireanas tem como característica principal a transformação da realidade, com a possibilidade de construção do cuidado qualificado ${ }^{61}$. Destacase que a pedagogia de Paulo Freire serviu como referencial teórico da PNEPS pela sua relação com a formação permanente dos profissionais, a partir da problematização da realidade cotidiana $^{62}$. A proposta de Paulo Freire segue com as necessidades do SUS, uma vez que considera o indivíduo como um agente ativo, que necessita ser empoderado e reconhecido como figura central.

Assim, é importante destacar que a EPS promove a melhoria da gestão do trabalho por fortalecer e valorizar a relação entre a equipe, criar e facilitar espaços de trocas e produção do conhecimento, além de ampliar o diálogo ${ }^{63}$. A EPS também tem como finalidade contribuir para cada coletivo analisar o próprio trabalho e ampliar a sua capacidade de responder às necessidades dos usuários, através da reinvenção do seu mundo de trabalho, em especial64. Nesta perspectiva, pode-se observar que os trabalhadores Caps aproximam-se de tal premissa ao perceberem que podem modificar hábitos arraigados e estimular práticas colaborativas e pautadas na ação-reflexão-ação, ou seja, propor mudanças que tragam melhorias para a qualidade do trabalho ${ }^{31-33,35-37,39,41,43,52}$.

Os trabalhadores Caps $\mathbf{3 7 , 3 9 , 4 1}$ destacam o papel fundamental do repensar transformador das práticas instituídas. Além disto, se aproximam das concepções aqui discutidas e descrevem a importância de transformar a realidade a partir do processo de trabalho, no qual deve haver reflexão e responsabilidade compartilhada. Neste sentido, os trabalhadores destacam que educação permanente é coisa do dia a dia, e que fazem a EPS em quase todo momento, dentro do serviço ${ }^{\mathbf{4 1}}$. Logo, os estudos revelam que a inserção de metodologias ativas, como a problematização em contexto de $\operatorname{Caps}^{\mathbf{3 1}, \mathbf{3 3}}$, possibilita a percepção da autonomia e o aprendizado dos trabalhadores, bem como garante espaços de reflexão nas instituições de saúde mental. Tal situação contribui para um desvio do saber tradicional hegemônico, e para o respeito aos contextos e às singularidades de cada serviço.

A concepção de EPS pelos trabalhadores Caps também se aproximou do conceito de EC, com ações técnicas e de atualização do saber. Profissionais e gestores Caps referem que realizar a EPS é formatar capacitações a partir de uma necessidade ou demanda, e que, através dela, poderiam resolver muito mais

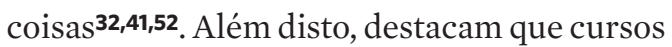
e capacitações contribuem para a atualização de conhecimentos. Porém, entende-se que a EC emerge da necessidade de capacitar grupos de trabalhadores da saúde inseridos nos serviços, com o predomínio de uma concepção de educação instrumental, que enfatiza ações técnicas de aquisição sequencial e acumulativa de informações, organizadas de forma vertical, por meio de cursos e treinamentos com foco nas categorias profissionais ${ }^{65,66}$.

Nessa direção, torna-se importante destacar que capacitação técnica e EPS seguem juntas no cenário de trabalho em saúde mental, fomentando práticas comprometidas com o cuidado integral, promotoras de autonomia para os usuários e de sentido para 
os profissionais. Uma não exclui a outra; ao contrário: agregadas, podem potencializar as mudanças e fortalecer as diretrizes da RPB ${ }^{41}$. A EC faz parte da EPS, que tem como pressuposto a aprendizagem que abrange a prática diária dos profissionais, e esse viés rompe com a lógica tradicional dos procedimentos técnicos estabelecidos e remete à singularização dos processos de cuidado, construídos de maneira compartilhada ${ }^{67}$.

Ao longo das discussões, em uma vivência com trabalhadores de um Caps Álcool e Drogas (Caps AD $)^{68}$, percebeu-se um paradoxo: por um lado, a iniciativa da equipe, de buscar formação de maneira autogestionária. Por outro lado, há uma expectativa do grupo por uma organização mais formal do processo de ensino-aprendizagem em serviço. Além disto, a equipe relatou acreditar que uma discussão teórica pode reverberar na prática, pois nesse processo de absorção de informação há alguma mudança ${ }^{68}$. Portanto, nesta experiência há uma lógica educacional centrada na reprodução de conceitos e práticas instituídas na educação tradicional ou bancária.

Ainda nessa perspectiva, a EPS também foi uma questão levantada pelos sujeitos de outro estudo, e está relacionada com a qualidade das atividades oferecidas pelos serviços ${ }^{52}$. Além disso, os coordenadores desses equipamentos de saúde mental também mencionaram a necessidade de capacitações e atualizações para minimizar as dificuldades. Tal olhar também evidencia o direcionamento do modelo tradicional de educação, pautado no saber técnico-científico, a partir da transferência de conteúdo. Assim, Stroschein e Zocche ${ }^{69}$ defendem que a EPS não se torna efetiva quando dá espaço para a reprodução de práticas de cuidado e formas de pensar individuais e enraizadas no modelo tradicional de atenção.

$\mathrm{Na}$ medida em que a EPS deixa de existir, considera-se que a efetivação da PNSM fica prejudicada, pois não há discussões inerentes ao exercício profissional52. Na clínica dos Caps, onde se trabalha com sofrimento psíquico, é importante colocar na roda os problemas que surgem no cotidiano, em busca do empoderamento dos trabalhadores ${ }^{68}$. Logo, como não se distanciar da lógica da EPS em uma prática formal/tradicional? É importante que a EPS e a EC sejam complementares e não substitutivas, para que os atravessamentos do cotidiano mantenham 'viva' a forma autônoma e criativa das equipes de atenção psicossocial.

\section{Produção do cuidado e a aproximação com a EPS nos Caps}

A RPB surge como um processo ético, político e social, que busca pautar uma série de ressignificações no modelo de cuidado em saúde mental, afetando trabalhadores, usuários, familiares e gestores, além de apresentar significativa interferência no território e no imaginário das pessoas envolvidas ${ }^{\mathbf{1 2}}$. Os Caps surgem neste processo com o objetivo de viabilizar a desinstitucionalização. Assim, na saúde mental, o vínculo, a rede e a integralidade são operadores fundamentais para a execução de um trabalho alinhado às diretrizes e à construção de uma efetiva rede de cuidados ${ }^{39}$.

Os resultados do presente estudo revelaram a produção do cuidado realizado pelos profissionais do Caps no cotidiano do trabalho e a aproximação com a EPS. Das 28 publicações, em 23 (82,14\%) delas foi evidenciada a produção do cuidado nos Caps 32,33,35-49,51,52,54,55,58. Ainda que a RPB tenha impulsionado avanços significativos no campo das práticas de cuidado em saúde mental, no modelo de atenção psicossocial, o modelo manicomial não foi totalmente vencido ${ }^{32}$. Para compreender esse processo concebido na lógica territorial, serão aqui analisados os artigos que desembocam nesse desfecho ${ }^{32,35-37,43,44}$. O Caps deve acolher os usuários de um determinado território e encaminhá-los, quando necessário, a outros equipamentos e serviços referentes ao mesmo território ${ }^{43}$. Eles configuram serviços de base territorial. Milton Santos ${ }^{70}$ discute a dimensão geopolítica do território, colocando em foco as produções sociais destes - em especial, políticas e carregadas de subjetividades. 
A organização dos serviços, por outro lado, possibilita que o território de responsabilidade dos Caps seja considerado muito grande para a reduzida equipe de pessoal, como destacado por um profissional, que afirmou que os quadros de saúde mental, ainda que leves e moderados, são todos direcionados para os Caps III ${ }^{35}$. Assim, é possível refletir sobre as dificuldades encontradas e a importância das ações de mapeamento do território vivo ${ }^{71}$. Este se configura a partir do planejamento e da sequência de ações e arranjos territoriais mais favoráveis a um rendimento máximo na organização da vida individual e coletiva das pessoas.

Nesse caminho, no estudo realizado por Evangelista et al. ${ }^{36}$, as ações com base territorial desenvolvidas pelos residentes ultrapassaram os muros dos Caps - o que foi ilustrado, nas falas, por "sair do Caps", "fora do Caps" ou "extra Caps" - como pressupostos da RPB e repletos de possibilidades para responder à necessidade de saúde da comunidade. Os trabalhadores ressaltaram a relevância e o contínuo desafio da atuação com base no território, orientando processos de desinstitucionalização de pessoas com agravos em saúde mental ${ }^{36}$. Por outro lado, psicólogos que atuam no Caps relatam que não reconhecem o trabalho territorial como prática psicológica ${ }^{\mathbf{4 8}}$. Aqui, é possível observar uma aproximação com a clínica tradicional nos Caps e um distanciamento do olhar para o usuário no território, com seus condicionantes.

É importante salientar que o conceito de território é apreendido de formas distintas no campo da saúde. Para os profissionais do Caps III de João Pessoa (PB), ser de base territorial implica demarcar sua vinculação a um conjunto de equipamentos e outros serviços, com vistas à atenção à saúde de um grupo populacional, em um dado território geográfico ${ }^{43,72}$. Assim, os Caps têm como função ordenar as redes de cuidado, possibilitando encaminhamentos dos usuários em fluxos. Porém, em uma reunião de equipe, um profissional apontou a dificuldade para articular o território com as redes informais. Ele defendeu a importância de conexões/parcerias com grupos comunitários presentes nos territórios ${ }^{43}$. O desconhecimento da vida pulsante nas esquinas das casas dos usuários é imenso, dado que os profissionais não sabem dizer, sem consultar os prontuários, em que bairros vivem esses usuários.

O trabalho em redes é relacional e configura uma forma de cuidar que se sustenta nas interações entre os sujeitos ${ }^{39}$. Neste sentido, estudos destacam as subjetividades, as demandas e os conflitos de uma rede que não é inerte ${ }^{39,42-44,48,58}$. Pinho et al. ${ }^{\mathbf{4 2}}$ dizem que, nos serviços de saúde mental que trabalham com álcool e outras drogas, a intersetorialidade parece urgente, dada a impossibilidade de os serviços responderem sozinhos às demandas e complexidades dos sujeitos. Eles seguem afirmando que o cuidado ao usuário de crack está centrado em uma rede fragmentada. Porém, os gestores apresentam uma avaliação diferente ao dizerem que os serviços são visíveis e reconhecidos. Assim, surge uma questão crucial, que é a necessidade de pensar quais recursos devem ser considerados, pelas equipes Caps, como passíveis de acionamento frente a esse paradigma ${ }^{43}$. Afinal, o trabalho em rede vem ganhando movimento ${ }^{\mathbf{4 8}, 58}$ e é caracterizado como um importante indicador ${ }^{44}$ para reorientar o modelo de atenção em saúde mental. O modelo encontrado pelos profissionais Caps para a produção desse indicador evidencia a importância do trabalho compartilhado para captar as capacidades do trabalho interprofissional e intersetorial.

É importante destacar que muitos profissionais relataram a falta de formação acadêmica para a atuação em grupos de cuidado em saúde mental ${ }^{32,33}$. Desta forma, a EPS contribui para um movimento de ressignificações, colocando o processo de trabalho em análise e dando visibilidade a formas cristalizadas enquanto fornece subsídios para novas formas de cuidado ${ }^{43}$. A EPS é um dispositivo importante para esse cenário, já que contribui para mudanças nas práticas em saúde, considerando a integralidade como um princípio da formação profissional ${ }^{49}$. Assim, nos debates 
travados entre os membros da equipe, alguns profissionais trouxeram as concepções que norteiam o cuidado ofertado em saúde mental. Um profissional do Caps afirmou que muitos trabalhadores da própria equipe apresentam lógicas manicomiais e não oferecem assistência de acordo com as diretrizes do Caps ${ }^{43}$. Para Onocko-Campos ${ }^{73}$, o processo de RPB e luta antimanicomial tem criado focos de cegueira e espaços recalcados de esvaziamento da discussão da clínica nos serviços substitutivos de saúde mental.

Apesar da RPB, alguns profissionais de saúde percebem o portador de transtorno mental como um 'paciente' incapaz de exercer seus direitos e deveres ${ }^{55}$. Além disto, a fragmentação do saber e a pouca articulação entre os profissionais no desenvolvimento de práticas multiprofissionais são fatores a serem reformulados, a fim de que realizem processos de cuidado mais condizentes com as demandas dos usuários ${ }^{49}$. Neste ínterim, torna-se importante apontar a necessidade de uma clínica para além da tradicional e avançar na discussão sobre a eficácia do cuidado em saúde mental. A clínica ampliada ${ }^{\mathbf{4}}$ traz aproximações com a clínica peripatética, como descreve Lancetti ${ }^{74}$, praticada em movimento, no 'dentro-fora' dos consultórios, nos espaços e tempos traçados. A aproximação com as realidades locais favorece que a EPS possa ser uma estratégia facilitadora de leitura dos contextos, além de provocar modificações no cuidado em saúde mental, de mãos dadas com a RPB ${ }^{41}$.

Embora os profissionais reconheçam a importância da escuta ${ }^{35,45}$ e do vínculo ${ }^{52}$ como formas de atenção e suporte, também identificam obstáculos para o cuidado diferenciado. Eles relatam que a quantidade insuficiente de profissionais dificulta o acolhimento e a escuta de forma singular. Um efeito que aparece nas tensões do cotidiano de trabalho é a transferência de responsabilidade, por parte das equipes, nas discussões sobre a produção do cuidado $^{\mathbf{4 0}}$. O discurso pelo 'comum' aparece nas falas dos trabalhadores de um Caps AD, em busca de uma equipe mais homogênea.
Porém, como os usuários possuem características heterogêneas, a pluralidade em busca da equidade, e não da igualdade, seria a ferramenta mais eficaz enquanto princípio do SUS para acolher os diferentes ${ }^{68}$.

Vasconcelos et al. ${ }^{46}$ fomentam discussões a partir da corresponsabilização entre equipe, usuários e família, na perspectiva da produção da autonomia, em dois Caps da Região Metropolitana de Fortaleza (CE). Por outro lado, os desafios crescem em diferentes equipamentos de saúde mental. Certa equipe de um Caps Infantojuvenil (Capsi), por exemplo, destacou as crianças pela pouca visibilidade no cenário da saúde como um todo, assim como em relação à saúde mental, e a falta de formação profissional para atuar com crianças e adolescentes ${ }^{47}$. Nesta perspectiva, o cuidado pode ser direcionado, em muitos casos, à família, não considerando os desejos, a responsabilidade e a subjetividade da criança.

A responsabilização no cuidado também foi evidenciada nas falas de outros profissionais, como estratégia para viabilizar a atenção contínua ${ }^{39}$, destacando a família como essencial nesse processo. No tratamento dos usuários, os familiares são fatores importantes, que contribuem para que o cuidado também seja direcionado ao núcleo social, e influenciam a recuperação do usuário Caps $\mathbf{3 8}^{\mathbf{3 8}} \mathbf{4 5 , 5 1 , 5 8}$. Assim, reforça-se a importância da inclusão de todos os envolvidos na prática do cuidar, a fim de estimular a promoção da autonomia dos sujeitos.

\section{Fatores intervenientes e características da EPS nos Caps}

As evidências em relação aos fatores intervenientes e às características da EPS nos Caps identificam os problemas atrelados à dificuldade de operacionalização dos serviços, tais como: limites de tempo e pouco incentivo dos gestores; deficit na formação acadêmica de profissionais e gestores; vínculos empregatícios precários; desvalia no processo de transformação; falta de conhecimento dos procedimentos Caps; ausência de qualificação; 
impossibilidade de registro dos profissionais que atuam no Caps, no Cadastro Brasileiro de Ocupações (CBO); sobrecarga no processo de trabalho; não reconhecimento de espaços de formação; e precariedade de recursos físicos, humanos e materiais. Alguns destes fatores se assemelham aos encontrados em revisão sobre a EPS na APS75 e no processo de trabalho nos Caps $^{76}$. Desta forma, apontam, em consonância com o presente estudo, as deficiências que precisam ser enfrentadas para que ocorra a legitimação de uma política educativa com a valorização das atividades psicossociais.

Das 28 publicações analisadas, 16 (57,14\%) evidenciaram os fatores intervenientes e características da EPS nos Caps ${ }^{31-35,37,38,40,42,50-}$ 53,55,57,58. No estudo de Pinheiro, Hypólito e Kantorski ${ }^{\mathbf{3 1}}$, os profissionais percebem a EPS como instrumento de trabalho que possibilita reflexões e problematizações, porém relatam a dificuldade de operacionalização com os limites de tempo e o pouco incentivo dos gestores. Abrahão, Azevedo e Gomes ${ }^{\mathbf{4 0}}$ também destacam, nas narrativas dos profissionais, a falta de investimento da gestão em ações de formação no serviço, assim como a emergência de um sentimento de não reconhecimento e de desvalorização dos seus trabalhos.

Nessa direção, outro estudo ${ }^{52}$ refere que os coordenadores também sinalizam a falta de incentivo e de consentimento, por parte dos gestores municipais, para que frequentem cursos de especialização. Os profissionais destacam uma necessidade frequente de apoio e de suporte da gestão no campo da formação na atenção psicossocial, pois a ausência desse tipo de atitude pode prejudicar a participação dos profissionais em busca de formação específica. Por exemplo, a enfermeira de um Caps AD afirma que, para participar de capacitações, é necessário que o profissional faça reposição de sua carga horária, o que contribui para a baixa procura por tais iniciativas, mesmo quando os cursos de capacitação são gratuitos ${ }^{57}$.

Os trabalhadores relataram que a seleção profissional geralmente ocorre por concursos públicos, processos seletivos e estratégias de recrutamento, que levam em conta os conhecimentos adquiridos na universidade, quase sempre, por meio da educação bancária ${ }^{33}$. Silva, Camargo e Bezerra ${ }^{34}$ relatam que esses profissionais constantemente se referem a uma ausência de qualificação e, consequentemente, a um desconhecimento dos procedimentos Caps.

Em outro estudo, os trabalhadores Caps AD relataram a distância entre o que é ensinado na academia e o que é evidenciado na realidade dos serviços de saúde ${ }^{37}$. E completaram, dizendo que as universidades não vêm conseguindo preparar profissionais para o comprometimento e a responsabilidade do trabalho no SUS e na saúde mental. É importante levar em consideração os resultados aqui encontrados, pois representam limites no processo de formação, e é preciso avançar diante dessas fronteiras.

Os coordenadores Caps apontam a superficialidade com que a saúde mental é abordada nos cursos de graduação, destacando que é comum receberem profissionais sem formação especializada em saúde mental. No entanto, ainda assim, não são oportunizados momentos de capacitação ${ }^{52}$. Diante disso, a qualificação profissional se torna distante da $\mathrm{RPB}^{55,57}$.

Nesse sentido, Onocko-Campos et al. ${ }^{58}$, em um estudo de avaliação da gestão dos Caps, destacam os indicadores construídos por profissionais do Caps III. Assim, foi proposto o questionamento sobre a participação dos gestores nas decisões clínicas e de formação continuada. Também enfatizou-se a necessidade de capacitações de qualidade e de flexibilização da gestão para a participação dos trabalhadores nos processos de formação permanente. É importante identificar avanços na construção dos indicadores, mas cabe aqui a reflexão: Qual o impacto de envolver os trabalhadores em ações de EPS com um forte desequilíbrio na relação de poder com os gestores ${ }^{61}$ ?

Nunes et al..$^{33}$ destacam que a maioria dos profissionais envolvidos na ação de EPS possuía vínculos empregatícios precários e fragilizados, em um estudo com 29 Caps, de 23 municípios da Região Centro-Oeste brasileira. 
Nota-se que, ao se somar a insatisfação dos vínculos empregatícios ${ }^{52,58}$ à sobrecarga do dia a dia, aos conflitos e à precariedade dos recursos físicos, materiais e humanos ${ }^{\mathbf{4 0 , 5 3 , 5 8}}$ e às diferenças nos regimes de trabalho e na condição salarial entre médicos e demais categorias ${ }^{52}$, é possível perceber os obstáculos para que os profissionais não acreditem na mudança do contexto em que estão inseridos. Além disso, em Goiás, os profissionais destacaram a falta de inclusão de determinadas categorias profissionais no $\mathrm{CBO}^{34}$. Por exemplo, as ações desenvolvidas por farmacêuticos, nutricionistas, educadores físicos, arteterapeutas ou psicopedagogos não podem ser registradas. Ou seja, os profissionais não se sentem incluídos nos Caps. Desta forma, é importante destacar a posição dos profissionais Caps na ação de EPS quando abandonaram o curso com o sentimento de desvalia no processo de transformação ${ }^{33}$.

Corroborando os resultados encontrados nas publicações selecionadas, os profissionais estavam imersos no cotidiano de trabalho sem espaços para reflexão ${ }^{40}$. As narrativas chamam a atenção para o não reconhecimento de espaços criativos para a produção do conhecimento. Em consonância, o grupo de um Caps AD relata a não necessidade de demarcar espaços de educação permanente, também percebendo a dificuldade de manterem uma agenda de encontros de formação ${ }^{68}$. Costa et al. ${ }^{50}$ identificam que alguns entrevistados de um Caps III consideram o apoiador como alguém que deve transmitir o conhecimento. Já Silva, Ness, Guanaes-Lorenzi ${ }^{\mathbf{3 8}}$, durante um registro reflexivo em um Caps III, descrevem o momento crítico de um facilitador ao compartilhar seu sentimento e sua avaliação diante de um grupo que estava paralisado em um ciclo de problemas. Em tais situações, percebem-se os desafios da busca pela EPS nos serviços de saúde mental em sua dimensão política.

Azevedo et al. ${ }^{51}$ destacam que a capacitação em saúde mental foi a temática mais referida na última questão da entrevista em um Caps III, como uma preocupação levantada pelos participantes. Nesse mesmo estudo, notou-se um predomínio de profissionais jovens, o que indica uma formação recente na área. Foram levantadas questões relacionadas à formação desses trabalhadores, destacando-se positivamente os profissionais, no processo de trabalho, pela não vivência no modelo manicomial, o que evita práticas contrárias à RPB. Por outro lado, afirmaram que a formação desses trabalhadores não desenvolveu conhecimentos em atenção psicossocial, o que pode prejudicar a assistência à saúde. Outra questão levantada foi a necessidade de incluir os gestores municipais nos processos de capacitação profissional, pois muitos não compreendem a PNSM.

Minozzo e Costa ${ }^{53}$ identificam a falta de comunicação e articulação entre os profissionais. Foi percebido o trabalho isolado de cada especialidade, o que gera falta de integração e de troca entre os profissionais. Além disso, as reuniões de equipe foram caracterizadas como espaços de falta de objetividade, dificuldade de escuta entre os colegas e pouca circulação da palavra, o que também despotencializa a comunicação e as trocas profissionais. Tais características demonstram a necessidade de maiores investimentos na qualificação, por meio da educação permanente dos profissionais que atuam nos Caps, a fim de atender às premissas da PNSM e da RPB.

\section{Fatores facilitadores e dispositivos de EPS nos Caps}

É no contexto e nas ações realizadas que os fatores facilitadores no cotidiano dos serviços contribuem para que a EPS encontre maneiras de se inserir e ampliar olhares com possibilidades de problematizar, repensar e rever os processos de trabalho em saúde. Segundo Merhy ${ }^{77}$, todo processo comprometido com a educação permanente precisa ter força para gerar, no trabalhador, na produção do cuidado em saúde, transformações de sua prática, o que implica problematizar a si mesmo no agir.

Após a análise dos artigos selecionados no presente estudo, as evidências indicaram 
agentes facilitadores e dispositivos como meios de desenvolver a EPS nos Caps: espaços de EPS por meio do diálogo; capacitações; cursos; seminários; reuniões de equipe; fórum intersetorial; cotidiano dos serviços; discussão de casos; trabalho em equipe; leitura de livros; apoio matricial; programas de residências; Programa de Educação pelo Trabalho/Rede de Atenção Psicossocial (PET-Raps); Projeto Terapêutico Singular (PTS); Projeto Terapêutico Individual (PTI); e supervisão clínico-institucional. Das 28 publicações, 26 (92,85\%) evidenciaram os fatores facilitadores e dispositivos de EPS nos Caps 31-33,35-50,52-58.

Estudos sobre educação permanente em saúde mental demonstram que momentos de diálogos em uma perspectiva 'espaço-como' são importantes, como em cursos, capacitações, seminários, reuniões de equipe, fóruns ou no próprio cotidiano dos servi$\operatorname{çs}^{\mathbf{3 1}, 41,42}$. As reuniões de equipe são consideradas pelos profissionais como espaços de resgate de suas experiências cotidianas, a fim de ressignificá-las, além de entendê-las como desencadeadoras de uma ação de

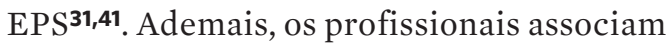
o conhecimento técnico e a reflexão sobre o que esse conhecimento pode produzir na prática específica de cada contexto ${ }^{41}$.

Na observação realizada nos Caps II e $\mathrm{AD}$, multiplicavam-se os espaços compartilhados de produção do conhecimento e de cuidados em saúde, no horário do café, na hora do almoço, na oficina de convivência e nos diversos lugares onde os trabalhadores atuavam ${ }^{40}$. Em suas narrativas, eles exploravam a necessidade de apoio no campo da formação, no trabalho Caps, pela possibilidade de produzir estratégias inovadoras que ampliassem o cuidado em saúde mental. Em outro estudo, os profissionais entrevistados trouxeram os Fóruns da Rede de Atenção Psicossocial à referência de 'como' e em que 'espaços' se realiza a EPS ${ }^{41}$. Desta forma, entende-se que, nesses espaços, a EPS torna-se possível na medida em que possibilita o diálogo entre os diferentes atores do campo da saúde, favorecendo o surgimento do contraditório nesse encontro de atores.

Na discussão de casos, também se identifica uma atividade que permite informar, socializar, ensinar e aprender, planejar, avaliar e resolver problemas ${ }^{31}$. Assim, por meio do compartilhamento do conhecimento e da responsabilidade, os profissionais se sentem mais seguros e estabelecem uma relação de maior proximidade, tornando o cuidado em saúde mental menos problemático ${ }^{\mathbf{4 2}}$.

Cescon, Capozzolo e Lima ${ }^{35}$, em uma pesquisa-intervenção, destacam a importância dos encontros entre a equipe de um Caps III. Dessa maneira, foi possível resgatar a força e a disponibilidade para o encontro com o outro e a possibilidade de gerar coragem e apoio para modificar hábitos arraigados. Por conseguinte, a equipe se comprometeu a manter, para a EPS, encontros semanais com uma hora de duração, e a buscar estratégias para modificar o processo de trabalho e situações relacionadas à temática do suicídio.

Outro aspecto facilitador da EPS nos Caps mencionado por Vargas e Duarte ${ }^{57}$ diz respeito à iniciativa dos profissionais: os enfermeiros entrevistados descrevem a relação da busca de estratégias de conhecimento para atuar no Caps AD e afirmam que, na ausência de espaços formais com capacitações e especializações, eles adquirem informações na leitura de livros e pela própria convivência e troca de experiências com os outros profissionais da equipe $^{57}$. Nesta direção, Oliveira e Caldana ${ }^{48}$ trazem aspectos das práticas que os psicólogos dos Caps III, Capsi e Caps AD utilizam no trabalho que realizam: possibilidade/necessidade de criar; tentativa de superação ou diferenciação do modelo clínico tradicional; e a necessidade de reflexão permanente sobre o papel profissional.

Assim, percebe-se o reconhecimento do espaço cotidiano dos serviços como fator facilitador da EPS na atenção psicossocial, e o desenho de um coletivo de sujeitos críticos, produtores de si e de seus pares, na tentativa de lidar com as diversas situações. Para Ceccim ${ }^{78}$, a EPS é 
uma estética pedagógica para a experiência da problematização e a invenção de problemas. Essa estética pode ser considerada a partir de dispositivos que contribuam para a produção da EPS nos Caps. Após a análise dos dados, o apoio matricial foi o desfecho mais citado nos estudos selecionados $32,33,36,41-43,47,50-54$. O uso da pesquisa-ação, associada ao apoio matricial com a metodologia da aprendizagem vivencial, configurou um espaço seguro para o diálogo crítico e libertador ${ }^{33}$. Um lugar onde não havia ignorantes absolutos, nem sábios absolutos, mas havia trabalhadores da saúde que, em comunhão, buscavam saber mais.

Os profissionais destacam o matriciamento 'como' um dos 'espaços' possíveis para a realização da EPS ${ }^{41}$, sendo esta a pauta de quase todas as reuniões de equipe do Caps $\mathrm{III}^{\mathbf{4 3}}$. Os trabalhadores deste mesmo Caps apontam a falta de interesse e a apropriação teórica da Estratégia Saúde da Família. Na tentativa de dirimir tal dificuldade e representar a Raps, um único profissional do Caps assume a responsabilidade do matriciamento das equipes da APS. Minozzo e Costa ${ }^{53}$, em uma pesquisa-ação, sinalizam a necessidade de fortalecer o trabalho em equipe nos Caps, a fim de potencializar espaços de reflexão sobre o trabalho coletivo. Entendem que o trabalho em equipe é fundamental para que o apoio matricial se efetive na lógica da atenção psicossocial.

Para obter a eficácia que o apoio matricial busca, é necessário contar com uma rede de saúde mental bem articulada na perspectiva da RPB. Azevedo, Gondim e Silva ${ }^{55}$ identificam que, para os profissionais que compõem a rede, a EPS é uma grande aliada para gerar mudanças nessa situação. Ballarin, Blanes e Ferigato $^{56}$ seguem afirmando que entendem o apoio matricial como um momento privilegiado de práticas de ensino-aprendizagem, seja de diferentes profissionais, entre diferentes equipes ou com usuários e familiares, e o consideram como um movimento sinérgico à proposta de EPS.

O programa de Residência Integrada em Saúde Mental (RISM) potencializou a reflexão sobre a construção de uma sociedade sem manicômios, o desenvolvimento de práticas colaborativas e a resolução dos problemas encontrados como constituintes de espaços de EPS $^{36,37}$. Em alguns estudos, os entrevistados afirmam que, no Caps, todos os profissionais de nível superior têm residência ou especialização. Este modelo de atenção em saúde mental merece destaque pelas exigências dos residentes, de executarem ações condizentes com a RPB que superem a cultura de práticas ambulatoriais e hospitalocêntricas. Os profissionais apontaram reflexões no processo de 'fazer residência e ser residente', nas quais identificaram uma educação para a vida que tem como escola a própria vida, conhecida como efeito Paideia ${ }^{37,79}$. Desta forma, o trabalho se ressignifica na própria experiência de um trabalhador em formação no serviço. Assim, ele segue perguntando, olhando para si e para as vulnerabilidades enquanto trabalhador ${ }^{36}$.

Rézio et al. ${ }^{45}$ afirmam que o PET-Raps proporcionou aos profissionais do Caps II o aperfeiçoamento de suas práticas, a partir das fragilidades apresentadas e vivenciadas na assistência prestada no cotidiano. Seguem na constatação de que a presença dos estudantes nos serviços potencializou o aprimoramento dos profissionais no cuidado em saúde mental, enquanto provocadores de mudanças. Ou seja, os estudantes e residentes, no cotidiano dos serviços de saúde, acabam atuando como dispositivos de EPS por desencadearem processos de aprendizagem ${ }^{36,37,45,49}$. Rosa et al. ${ }^{49}$ destacam que o PET-Raps tem o papel de incentivar a formação e qualificação técnica dos profissionais de saúde mais adequada às necessidades do SUS. Entre as ações de EPS destacadas pelos preceptores, estão: reuniões mensais do PET com tutores, preceptores e alunos; preceptoria em serviço; espaços de reunião em equipe e supervisão institucional; e busca de informações e pesquisa de material bibliográfico.

A supervisão é um dispositivo fundamental no campo da RPB. Silva et al.52 destacam que as supervisões clínico-institucionais são entendidas como atividades que qualificam 
e integram as equipes dos serviços de saúde mental, considerando casos clínicos e o contexto institucional (recursos do território, política pública e gestão). Onocko-Campos et al.44, a partir de um estudo avaliativo no Caps III, destacam a supervisão clínico-institucional como elemento integrante da EPS, juntamente com horas dedicadas à formação em espaços institucionais externos ao Caps, sendo a supervisão clínico-institucional e a formação externa definidas como indicadores para a formação continuada dos trabalhadores.

Ainda, Onocko-Campos ${ }^{80}$ considera que o modo de formação na supervisão deve ser sempre voltado para a transmissão de um modo de conhecer, e não um saber pronto, sendo esse modo de conhecer e o próprio conhecimento, processuais. Assim, o supervisor possibilita à equipe espaços de reflexão e a construção de projetos terapêuticos, que são considerados dispositivos para a superação do modelo manicomial. Ferreira et al. ${ }^{43}$ consideram que a elaboração do PTS permite uma construção dialógica entre profissionais, usuários e familiares, e pressupõe o reconhecimento do território existencial do usuário e suas redes vivas de cuidado ou descuidado, assim como linhas de fuga para a produção de novos modos de subjetivação.

Embora o projeto terapêutico possa transversalizar o processo de RPB, Vasconcelos et al. ${ }^{46}$ destacam a reflexão da equipe, o pensamento sobre projetos terapêuticos que se contraponham ao modelo hegemônico, e seguem, com base na diversidade de ações, com um olhar ampliado, através do qual cada unidade de saber provoca o encontro de possibilidades, de trocas e fazeres. Onocko-Campos et al. ${ }^{58}$, em um estudo avaliativo em seis Caps III, dizem que o PTI foi considerado como consolidado nos serviços, sendo avaliado periodicamente. Ainda assim, em relação a dispositivos avaliativos, foi sugerida a criação de oficinas para os trabalhadores Caps, com o objetivo de apresentar e discutir o trabalho e o PTI que fazem. Estas experiências singulares potencializam a necessidade de fortalecer a EPS nos Caps.
O presente estudo apresenta como limitação a não inclusão de dissertações e teses brasileiras sobre a EPS nos Caps, restringindo-se à análise da produção publicada no formato de artigos científicos. Por outro lado, seguiu o rigor metodológico em todas as suas etapas, destacando-se a realização da avaliação da qualidade metodológica dos estudos incluídos, classificada, em sua maioria, como alta. Sugere-se que os próximos estudos sobre a EPS nos Caps considerem os pontos limitantes dos estudos selecionados, como a ausência da explicitação entre pesquisador e pesquisado; procedimentos metodológicos apresentados e discutidos; e cuidados éticos.

\section{Considerações finais}

Esta revisão traz reflexões a respeito da EPS nos Caps brasileiros, nos últimos dez anos. O caráter integrativo revela deficiências e potencialidades na qualificação dos profissionais e gestores, sendo possível compreender e repensar a EPS com vistas à atenção psicossocial. Neste estudo, identificou-se a ausência da educação permanente como uma política institucional, além do fato de as ações de formação desenvolvidas ainda estarem distantes das transformações desejadas no âmbito da saúde mental.

A concepção de EPS pelos gestores e trabalhadores Caps aproxima-se da compreensão da EC, com ações técnicas e de atualização do saber. Embora reconheçam que a EPS possibilita reflexão e problematização das práticas, a produção do cuidado possui um distanciamento do olhar para o usuário no território, a partir de uma clínica tradicional. Ainda que, a RPB tenha impulsionado avanços, é necessário discutir os saberes e os fazeres das práticas profissionais para a promoção da autonomia e transformações permanentes sobre os modos de cuidar.

O pouco incentivo dos gestores, o deficit na formação acadêmica, os vínculos empregatícios precários, a desvalia no processo de transformação, a falta de conhecimento nos 
procedimentos Caps, a ausência de qualificação, a impossibilidade de registros no CBO, bem como a sobrecarga e a precariedade de recursos físicos, humanos e materiais estão presentes nos diversos equipamentos de saúde mental, no Brasil. Neste processo, é imprescindível entender as demandas reais das práticas de trabalho que contribuem para que as dificuldades possam ser enfrentadas e as mudanças efetivadas.

Por outro lado, há avanços a partir de buscas para ampliar olhares e possibilidades no próprio cotidiano de trabalho. Capacitações, cursos, seminários, reuniões de equipe, fórum intersetorial, diálogos, discussão de casos, trabalho em equipe, apoio matricial, programas de residência, PET-Raps, PTS/PTI e supervisão clínico-institucional também estão presentes como dispositivos de EPS, embora seja preciso aperfeiçoá-los na tentativa de compor a formação em serviço e superar os desafios que a clínica Caps requer.

Este estudo possibilita colocar o processo de EPS nos Caps em evidência e levantar subsídios para aprimorar uma política educativa em saúde mental no Brasil. Por se tratar de um fenômeno multifacetado, torna-se importante a corresponsabilização, para que todos os atores envolvidos reconheçam a mudança institucional e de transformação à luz da RPB e da PNSM. Para isto, sugere-se o desenvolvimento de instrumentos e indicadores que avaliem as ações da EPS nos Caps para fortalecer a relação entre profissionais, gestores, comunidade e instituições de ensino, contribuindo para que essa política se torne eficaz no modelo de atenção psicossocial.

\section{Colaboradores}

Mattos MP (0000-0002-8792-5860)* foi o responsável pela concepção e pelo desenho da pesquisa, pela obtenção, análise e interpretação dos dados e da redação do manuscrito. Campos HMN (0000-0001-5413-9110)* e Gomes DR (0000-0002-1831-1259)* responsabilizaram-se pela obtenção e análise dos dados, e pela redação do manuscrito. Ferreira L (0000-00015707-5677)*, Carvalho RB (0000-0001-85223577)* e Esposti CDD (0000-0001-8102-7771)* orientaram a concepção e o desenho da pesquisa, a interpretação dos dados e a revisão do manuscrito. 


\section{Referências}

1. Batista KBC, Gonçalves OSJ. Formação dos profissionais de saúde para o SUS: significado e cuidado. Saúde Soc. 2011; 20(4):884-899.

2. Rovere M. Gestion estratégica de La educación permanente en salud. In: Haddad J, Roschke MALC, Davini MC, organizadores. Educación Permanente de Personal de Salud. Washington: Organización Panamericana de la Salud; 1994. (Série Desarrollo de Recursos Humanos no 100. p. 63-106).

3. Organização Pan-Americana da Saúde. Educación permanente de personal de salud en la región de las Américas. Washington: OPAS; 1988. (Fascículo I: Propuesta de reorientación. Fundamentos. Serie de desarrolo de recursos humanos, $\mathrm{n}^{\circ} 78$ ).

4. Lemos CLS. Educação Permanente em Saúde no Brasil: educação ou gerenciamento permanente? Ciênc. Saúde Colet. 2016; 21(3):913-922.

5. Brasil. Constituição, 1988. Constituição da República Federativa do Brasil. Brasília, DF: Senado Federal; 1988.

6. Brasil. Ministério da Saúde, Secretaria de Gestão do Trabalho e da Educação na Saúde. Política de Educação Permanente e Desenvolvimento para o SUS: caminhos para educação permanente em saúde. Brasília, DF: Ministério da Saúde; 2004. (Série C. Projetos, Programas e Relatórios).

7. Brasil. Ministério da Saúde. Portaria n 198/GM/MS, de 13 de fevereiro de 2004. Institui a Política Nacional de Educação Permanente em Saúde como estratégia do Sistema Único de Saúde para a formação e o desenvolvimento de trabalhadores para o setor, e dá outras providências. Diário Oficial da União. 14 Fev 2004.

8. Brasil. Ministério da Saúde. Portaria GM/MS n ${ }^{0} 1.996$, de 20 de agosto de 2007. Diretrizes para a implementação da Política Nacional de Educação Permanente. Diário Oficial da União. 21 Ago 2007.
9. Brasil. Ministério da Saúde, Secretaria-Executiva. Glossário temático: gestão do trabalho e da educação na saúde [internet]. 2. ed. Brasília, DF: MS; 2012. [acesso em 2019 out 20]. Disponível em: http://bvsms.saude.gov.br/bvs/publicações/glossario_gestao_ trabalho_2ed.pdf.

10. Peduzzi M, Guerra DAD, Braga CP, et al. Atividades educativas de trabalhadores na atenção primária: concepções de educação permanente e de educação continuada em saúde presentes no cotidiano de Unidades Básicas de Saúde em São Paulo. Interface (Botucatu). 2009; 13(30):121-134.

11. Campos FE, Pierantoni CR, Haddad AE, et al. Os desafios atuais para a educação permanente no SUS. Cad. RH Saúde. 2006; 3(1):41-45.

12. Brasil. Ministério da Saúde. Reforma Psiquiátrica e política de saúde mental no Brasil. Relatório Conferência Regional de Reforma dos Serviços de Saúde Mental: 15 anos depois de Caracas. Brasília, DF: Ministério da Saúde; 2005.

13. Desviat M. A Reforma Psiquiátrica. Rio de Janeiro: Fiocruz; 2002.

14. Pitta AMF. Um balanço da reforma psiquiátrica brasileira: instituições, atores e políticas. Ciênc. Saúde Colet. 2011; 16(12):4579-4589.

15. Brasil. Ministério da Saúde. Portaria no 3.088, de 23 de dezembro de 2011. Dispõe sobre a Rede de Atenção Psicossocial para pessoas com sofrimento ou transtorno mental e com necessidades decorrentes do uso de crack, álcool e outras drogas, no âmbito do Sistema Único de Saúde. Diário Oficial da União. 24 Dez 2011.

16. Almeida JMC. Política de saúde mental no Brasil: o que está em jogo nas mudanças em curso. Cad. Saúde Pública. 2019; 35(11):e00129519.

17. Sousa PF, Maciel SC, Medeiros KT, Paradigma biomédico x psicossocial: onde são ancoradas as repre- 
sentações sociais acerca do sofrimento psíquico? Temas Psicol. 2018; 26 (2):883-895.

18. Guimarães TAA, Rosa LCS. A remanicomialização do cuidado em saúde mental no Brasil, no período de 2010-2019: análise de uma conjuntura antirreformista. Rev. Depart. Serv. Soc: O Social em Questão. 2019; (44):111-138.

19. Brasil. Ministério da Saúde. Portaria n ${ }^{0} 3.588$, de 21 de dezembro de 2017. Altera as Portarias de Consolidação $n^{0}$ 3/GM/MS e nº 6/GM/MS, de 28 de setembro de 2017, para dispor sobre a Rede de Atenção Psicossocial, dá outras providências e inclui procedimentos de Tratamento em Psiquiatria na Tabela de Procedimentos, Medicamentos, Órteses, Próteses e Materiais Especiais do SUS. Diário Oficial da União. 22 Dez 2017.

20. Onocko-Campos RT. Saúde mental no Brasil: avanços, retrocessos e desafios. Cad. Saúde Pública. 2019; 35(11):e00156119.

21. Brasil. Ministério da Saúde. Nota Técnica $n^{0}$ 11/2019-CGMAD/DAPES/SAS/MS. Esclarecimentos sobre as mudanças na Política Nacional de Saúde Mental e nas Diretrizes na Política Nacional sobre Drogas. Brasília, DF: Ministério da Saúde; 2019.

22. Guljor AP, Vasconcelos E, Couto MC, et al. Nota de Avaliação Crítica da Nota Técnica 11/2019 - Esclarecimentos sobre as mudanças na Política Nacional de Saúde Mental e nas Diretrizes na Política Nacional sobre Drogas [internet]. [acesso em 2019 out 15]. Disponível em: http://www.crprj.org.br/site/wp-content/uploads/2019/02/Note-tecnica-Saude-Mental. pdf.

23. Benito GAV, Franz MS. Educación permanente em la salud: Reflexiones em la perspectiva de la integralidad. Rev. Cubana de Enfer. 2010; 26(4):667-679.

24. Whittemore R, Knafl K. The integrative review: Updated methodology. J. Adv. Nurs. 2005; 52(5):546-553.

25. Ganong LH. Integrative reviews of nursing research. Res. Nurs. Heal. 1987; 10(1):1-11.
26. Moher D, Liberati A, Tetzlaff J, et al. Preferred Reporting Items for Systematic Reviews and Meta-Analyses: The PRISMA Statement (Reprinted from Annals of Internal Medicine). Phys. Ther. 2009; 89(9):873880.

27. Minayo MCS, organizadora. Pesquisa Social. Teoria, método e criatividade. 18. ed. Petrópolis: Vozes; 2016.

28. Critical Appraisal Skills Programme. Critical Appraisal Skills Programme making sense of evidence. London; Oxford: Public Health Resource Unit; University of Oxford; 2006.

29. Espíndola CR, Blay SL. Percepção de familiares sobre a anorexia e bulimia: revisão sistemática. Rev. Saúde Pública 2009; (43):707-16.

30. Magno L, Silva LAV, Veras MA, et al. Estigma e discriminação relacionados à identidade de gênero e à vulnerabilidade ao HIV/AIDS entre mulheres transgênero: Revisão Sistemática. Cad. Saúde Pública. 2019; 35(4):e00112718.

31. Pinheiro MCC, Hypólito ALM, Kantorski LP. Educação permanente no processo de trabalho em saúde mental. J. Nurs. Health. 2019; 9(2):e199203.

32. Vasconcelos MS, Barbosa VFB. Conhecimento de gestores e profissionais da rede de atenção psicossocial sobre matriciamento em saúde mental. Ciên. Cuid. Saúde. 2019; 18(4):e43922.

33. Nunes FC, Caixeta CC, Pinho ES, et al. A tecnologia grupal no cuidado psicossocial: Um diálogo entre pesquisa-ação e educação permanente em saúde. Texto Contexto Enferm. 2019; (28):e20180161.

34. Silva NS, Camargo NCS, Bezerra ALQ. Avaliação dos registros de procedimentos por profissionais de Centros de Atenção Psicossocial. Rev. Bras. Enferm. 2018; 71(5):2191-8.

35. Cescon LF, Capozzolo AA, Lima LC. Aproximações e distanciamentos ao suicídio: analisadores de um serviço de atenção psicossocial. Saúde Soc. 2018; 27(1):185-200. 
36. Evangelista ALP, Frota AC, Torres RBS, et al. Residência integrada em saúde mental: cuidado a rede de atenção psicossocial. Rev. Bras. Promoç. Saúde. 2018; 31(4):1-11.

37. Wetzel C, Kohlrausch ER, Pavani FM, et al. Análise sobre a formação interprofissional em serviço em um Centro de Atenção Psicossocial. Interface (Botucatu). 2018; 22(2):1729-38.

38. Silva GM, Ness O, Guanaes-Lorenzi C. Continuing education in mental health: critical moments to analyze group process. Paidéia. 2018. 28:e2834.

39. Bermudez KM, Siqueira-Batista R. "Um monte de buracos amarrados com barbantes": o conceito de rede para os profissionais de Saúde Mental. Saúde Soc. 2017; 26(4):904-919.

40. Abrahão AL, Azevedo FFM, Gomes MPC. A produção do conhecimento em saúde mental e o processo de trabalho no Centro de Atenção Psicossocial. Trab. Educ. Saúde. 2017; 15(1):55-71.

41. Leite LS, Rocha KB. Educação permanente em saúde: como e em que espaços se realiza na perspectiva dos profissionais de saúde de Porto Alegre. Estud. Psicol. 2017; 22(2):203-213.

42. Pinho LB, Silva AB, Siniak DS, et al. Análise da articulação da rede para o cuidado ao usuário de crack. Rev. Baiana Enferm. 2017; 31(1):e16654.

43. Ferreira TPS, Sampaio J, Souza ACN, et al. Produção do cuidado em Saúde Mental: desafios para além dos muros institucionais. Interface (Botucatu). 2017; 21(61):373-84.

44. Onocko-Campos R, Furtado JP, Trapé TL, et al. Indicadores para avaliação dos Centros de Atenção Psicossocial tipo III: Resultados de um desempenho participativo. Saúde debate. 2017; 41(esp):71-83.

45. Rézio LA, Caetano DAF, Borges FA, et al. The PET-Networks as transformer of practices of a Psychosocial Care Center. Interface (Botucatu). 2017; 21(60):8998.
46. Vasconcelos MGF, Jorge MSB, Catrib AMF, et al. Therapeutic design in Mental Health: practices and procedures in dimensions constituents of psychosocial care. Interface (Botucatu). 2016; 20(57):313-23.

47. Salvador DB, Pio DAM. Apoio matricial e Capsi: desafios do cenário na implantação do matriciamento em saúde mental. Saúde debate. 2016; 40(111):246256.

48. Oliveira TTSS, Caldana RHL. Psicologia e práticas psicossociais: Narrativas e concepções de psicólogos de centros de atenção psicossocial. Est. Interd. Psicol. 2016; 7(2):2-21.

49. Rosa M, Souza A, Abrahão AL, et al. Inovações na formação em saúde: o programa de educação pelo trabalho - Saúde Mental. Rev. Port. Enferm. Saúde Mental. 2016; (4):39-44.

50. Costa FRM, Lima VV, Silva RF, et al. Challenges of matrix support as educational practice: mental health in primary health care. Interface (Botucatu). 2015; 19(54):491-502.

51. Azevedo DM, Oliveira AM, Melo GSM, et al. Avaliação da assistência em saúde num Centro de Atenção Psicossocial na perspectiva dos profissionais. Rev. Bras. Pesq. Saúde. 2014; 16(2):109-116.

52. Silva NS, Esperidião E, Cavalcante ACG, et al. Desenvolvimento de recursos humanos para atuar nos serviços de saúde mental. Texto Contexto Enferm. 2013; 22(4):1142-51.

53. Minozzo F, Costa IIC. Apoio matricial em saúde mental entre CAPS e Saúde da Família: trilhando caminhos possíveis. Psico-USF. 2013; 18(1):151-160.

54. Minozzo F, Costa IIC. Apoio matricial em saúde mental: fortalecendo a saúde da família na clínica da crise. Rev. Latinoam. Psicopat. Fund. 2013; 16(3):438-450.

55. Azevedo DM, Gondim MCSM, Silva DS. Apoio matricial em saúde mental: percepção dos profissionais no território. R. Pesq.: Cuid. Fundam. 2013; 5(1):331122. 
56. Ballarin MLCS, Blanes LS, Ferigato SH. Matrix support: a study on the perspective of mental health professionals. Interface (Botucatu). 2012; 16(42):767-78.

57. Vargas D, Duarte FAB. Enfermeiros dos Centros de Atenção Psicossocial em Álcool e Drogas (CAPS AD): a formação e a busca pelo conhecimento específico da área. Texto Contexto Enferm. 2011; 20(1):119-26.

58. Onocko-Campos RT, Furtado JP, Passos E, et al. Avaliação da rede de Centros de Atenção Psicossocial: Entre a saúde coletiva e a saúde mental. Rev. Saúde Pública. 2009; 43(1):16-22.

59. Ceccim RB. Educação permanente em saúde: desafio ambicioso e necessário. Interface (Botucatu). 2005; 9(16):161-177.

60. Ceccim RB, Ferla AA. Educação permanente em saúde. In: Pereira IB, Lima JCF, organizadores. Dicionário da educação profissional em saúde. 2. ed. rev. ampl. Rio de Janeiro: EPSJV; 2008. p. 462-468.

61. Freire P. Pedagogia do Oprimido. Rio de Janeiro: Paz e Terra; 2013.

62. Sá TH, Florindo AA. Efeitos de um programa educativo sobre práticas e saberes de trabalhadores da Estratégia de Saúde da Família para a promoção de atividade física. Rev. Bras. Ativ. Fís. e Saúde. 2012; 17(4):293-299.

63. Medeiros AC, Pereira QLS, Siqueira HCH, et al. Gestão participativa na educação permanente em saúde: olhar das enfermeiras. Rev. Bras. Enferm. 2010; 63(1):38-42.

64. Merhy EE, Feuerwerker LCM, Ceccim RB. Educación permanente en salud: una estrategia para intervenir en la micropolítica del trabajo en salud. Salud Colect. 2006; 2(2):147-160.

65. Silva LAA, Soder RM, Petry L, et al. Educação permanente em saúde na atenção básica: percepção dos gestores municipais de saúde. Rev. Gaúch. Enferm. 2017; 38(1):1-8.
66. Weykamp JM, Cecagno D, Vieira FP, et al. Educação permanente em saúde na atenção básica: percepção dos profissionais de enfermagem. Rev. Enferm. UFSM. 2016; 6(2):281-289.

67. Lírio APS. O lugar do sensível na educação permanente em saúde: ausência, continuidade ou ruptura. Cad. Edu. Tec. Soc. 2016; 9(3):375-38.

68. Silva e Silva DL, Knobloch F. The team as a place of education: the continuing education in a Psychosocial Attention Center of alcohol and other drugs. Interface (Botucatu). 2016; 20(57):325-35.

69. Stroschein KA, Zocche DAA. Permanent education in health services: a study on the experience gained in Brazil. Trab. Educ. Saúde. 2012; 9(3):505519.

70. Santos M. Território: globalização e fragmentação. 4. ed. São Paulo: Hucitec; 1998.

71. Santos M. A Natureza do espaço: técnica e tempo, razão e emoção. 4. ed. São Paulo: Editora da Universidade de São Paulo; 2006.

72. Mendes EV. As redes de atenção à saúde. Ciênc. Saúde Colet. 2010; 15(5):297-305.

73. Onocko-Campos RT. Clínica: a palavra negada sobre as práticas clínicas nos serviços substitutivos de Saúde Mental. Saúde debate. 2001; 25(58):98111.

74. Lancetti A. Clínica Peripatética. Hucitec: São Pau1o; 2006.

75. Ferreira L, Barbosa JSA, Esposti CDD, et al. Educação Permanente em Saúde na atenção primária: uma revisão integrativa da literatura. Saúde debate. $2019 ; 43(120): 223-239$.

76. Pinho ES, Souza ACS, Esperidião E. Processos de trabalho dos profissionais dos Centros de Atenção Psicossocial: revisão integrativa. Ciênc. Saúde Colet. 2018; 23(1):141-151. 
77. Merhy EE. O desafio que a educação permanente tem em si: a pedagogia da implicação. Interface (Botucatu). 2005; 9(16):161-77.

78. Ceccim RB. Réplica. Interface (Botucatu). 2005; 9(16):175-177.

79. Campos GWS. Efeito paidéia e o campo da saúde: reflexões sobre a relação entre o sujeito e o mundo da vida. Trab. Educ. Saúde. 2006; 4(1):19-32.
80. Onocko-Campos RTO. Psicanálise \& saúde coletiva: interfaces. São Paulo: Hucitec; 2012.

Recebido em 01/12/2019

Aprovado em 18/08/2020

Conflito de interesses: inexistente

Suporte financeiro: não houve 